\title{
Comparative Study and Analysis of the Development of Shale Gas between China and the USA
}

\author{
Qianqian Wang*, Lu Wang \\ School of Earth Sciences and Resources, China University of Geosciences, \\ Beijing, China \\ Email: "wangqianqian_cn@163.com
}

Received 5 January 2016; accepted 26 February 2016; published 29 February 2016

Copyright (C) 2016 by authors and Scientific Research Publishing Inc.

This work is licensed under the Creative Commons Attribution International License (CC BY). http://creativecommons.org/licenses/by/4.0/

(c) (i) Open Access

\begin{abstract}
In the $21^{\text {st }}$ century, the shale gas is a greatly potential unconventional gas resource, which can serve as an important complement to conventional energy sources, and can effectively alleviate the energy pressure of the world. The development of shale gas in the USA is in the developing stage with advanced exploitation technology and huge reserves. Compared with the USA, the development of shale gas in China is still in the early stage. The development of shale gas is both an opportunity and a challenge. China is in the exploration and preparation stage of resource assessment and exploration. This paper presents the importance of the formation principle of shale gas and the energy application, and compares the progress of shale gas studies, exploitation technology as well as the study hot-points between China and the USA. Meanwhile, this paper states the difficulties and challenges with the development of shale gas in China.
\end{abstract}

\section{Keywords}

Shale Gas, Study Situation, Developmental Prospects, Exploitation Technology, Study Hot-Points

\section{Introduction}

Shale gas is an unconventional natural gas resource with immense potential in twenty-first Century, which can be an important supplement to conventional energy sources and can effectively relieve the pressure on the world's energy (Table 1). Shale gas is the natural gas in the shale beds [1], and is different from the conventional gas reservoir. The shale beds are not only the source rock of the natural gas, but also the reservoir rock and

"Corresponding author. 
Table 1. Distribution of the globe shale gas (after World Resources Institute [3]).

\begin{tabular}{cc}
\hline Countries & $\begin{array}{c}\text { Volume of recoverable shale resources } \\
\text { (trillion cubic meters) }\end{array}$ \\
Canada & 573 \\
United States & 567 \\
Mexico & 545 \\
Colombia & 55 \\
Paraguay & 75 \\
Argentina & 802 \\
Brazil & 245 \\
Venezuela & 167 \\
Egypt & 100 \\
Libya & 122 \\
Algeria & 707 \\
France & 137 \\
Poland & 148 \\
Ukraine & 128 \\
Russia & 287 \\
China & 1115 \\
India & 95 \\
Pakistan & 437 \\
South Africa & \\
Australia & 590 \\
\hline & \\
\hline
\end{tabular}

overlying strata for the concentration and preservation of natural gas. The accumulation mechanism is essentially a dynamic balance between occurrence states of natural gas in shale pore [2].

Shale gas is defined as natural gas from shale formations, with the shale acting as both the source and the reservoir for the natural gas. Shale gas is a kind of natural gas gathering in free and absorbent forms in shale bed. There is only the free shale gas in the cracks, while both free and absorbent shale gas are in the groundmass (Figure 1). Each of these shale gas basins is different and each has a unique set of exploration criteria and operational challenges. For China, the development of shale gas is both an opportunity and a challenge [4]. The United States is a huge energy consuming country in the world. Then, the US government hopes to seek more energy supply channels to change the passive situation, i.e. the large degree of dependence on oil. Over the past ten years, shale gas has become an increasingly important natural gas resource in the United States, and it has received wide attention from other countries around the world.

\section{Research of the Shale Gas}

\subsection{Research of the Shale Gas in the USA}

Shale beds in the USA are mainly developed in more than 20 basins of the North America platform with different sizes, while the commercial exploitations of shale gas are concentrated in five basins, i.e. Fort Worth, San Juan, Michigan, Appalachian and Illinois. After years of commercial operation, intensive well network has been arranged and generated enough scale of economic benefits. The recovery of shale gas is also improved up to $20 \%$ [6]. 


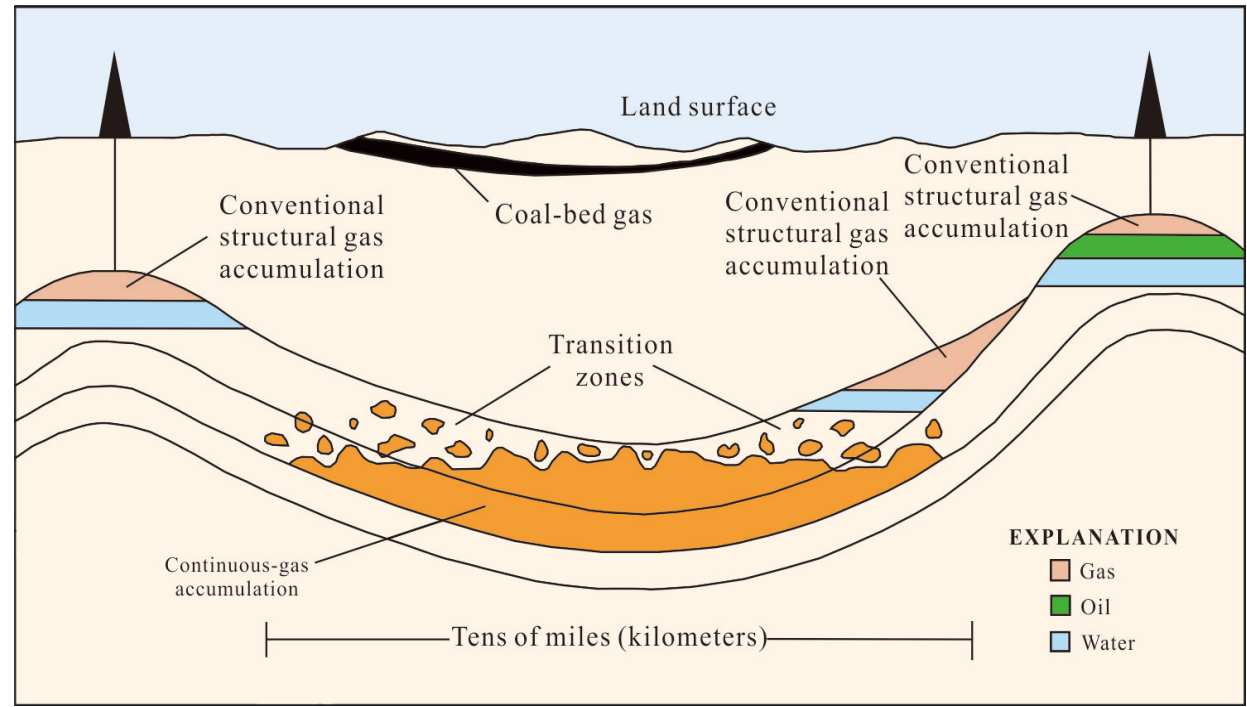

Figure 1. The relationship between shale gas and other types of oil and gas reservoir (revised from Schenk C. J. \& Pollastro R. M., 2001 [5]).

Combination of production, education and research is the secret of the success of the revolution of shale gas in the USA. It is the small and medium companies to promote the technology innovation and commercialization of the shale gas field in the USA, while the large companies promote the development of shale gas industry in the relatively mature stage. The main gas technology of shale gas mining in the USA is developed by the small and medium-sized energy companies and technology service corporations. Many companies take part in the process of a technology from research to commercialization. Small-medium sized companies and large companies have different roles during the development of shale gas. The former completes the technology and commercialization, while the latter takes advantage of the long-term and investment capabilities. Large companies can take the technology and production into large-scale in the late stage through the acquisition of shale gas block or mining technology of small-medium companies, or joint venture cooperation with small-medium companies. This social division and cooperation between the small-medium companies and large companies achieve a balance of the production and mining costs of shale gas industry, which promote the development of shale gas in the USA [7].

\subsection{Research of the Shale Gas in the China}

In the Asia Pacific region, the shale gas reserves are very rich in the China and Australia. The two countries as well as India, Indonesia has already started to investigate and exploration of shale gas resources.

The research of the shale gas in the China is late, and the first report about the shale gas was in the journal of "World Well Logging Technology" in the 4th volume of 1996. But until the classic article, i.e. "Fractured shale-gas systems” by J. B. Curtis, has been translated by Darong Li in 2002, the shale gas just started to be paid close attention by the domestic scholars [2]. The accumulation conditions, exploration and development of the shale gas in these basins have been studied substantially [8]-[12].

Through field geologic survey, analysis of drilling and logging information and sample experimental tests, The features of organic matter enriched shale distribution, organic geochemical features, reservoir characteristics has been studied, and gas bearing potential in the Lower Cambrian Niutitang Formation, Hunan-Guizhou area and the prospect of shale gas exploration is discussed [13]. The geological characteristics of the mud-shale strata and exploration potential of shale gas in the center and northeast of Hunan Province have been analyzed [14]. The main controlling factors of marine shale gas accumulation in the south of Sichuan and its adjacent areas have been studied [15]. Overall, the development of shale gas in China is still in the exploration and preparation stage of resource assessment and exploration. In July 2011, Ministry of land and resources in China held the first round of shale gas prospecting tender. All kinds of cooperation in the development, technical cooperation and studies have been started by the relevant departments and oil companies in China and the USA. 
Gas shale development in China has just started. The overall is in the exploration and preparation stage of resource assessment and exploration. In July 2011, China's Ministry of land and resources held the first round of gas shale prospecting tender. China's relevant departments and oil companies have also been working with the United States in the gas shale development, technical cooperation, research and other aspects of a variety of forms of cooperation.

Degree of shale gas development in the United States is more mature than in China, and the promotion of its shale gas mining technology relies mainly on small and medium-sized companies. However, the development of shale gas in China has just started, which needs the leadership of the national large-scale enterprises, so its main core technology concentrated in large enterprises.

\section{Developmental Prospects of Shale Gas}

The development of shale gas shale is system engineering, including many key technologies such as hydraulic fracturing technology, horizontal drilling technology, selection evaluation techniques, experimental analysis technology, micro-seismic monitoring technology, logging interpretation technology and three-dimensional seismic technology and so on. According to foreign experience, perfect infrastructure for natural gas production is one of the important criteria to evaluation of the development and use of shale gas.

\subsection{Developmental Prospects of Shale Gas in the USA}

In 2000, shale gas productions in the USA are 36.62 billion cubic meters, accounting for only $1 \%$ of total natural gas. While, by 2010, shale gas productions are up to 137.92 billion cubic meters (equivalent to $23 \%$ of total natural gas productions) because of the development of hydraulic fracturing technology, horizontal drilling technology and so on. In 2013, Energy Information Administration of the USA forecasted that $46 \%$ of natural gas productions will from shale gas by 2035 (Figure 2). It is not accidental for the huge success of the development of shale gas in the USA, to a large extent, which is depend on multi-factors such as the technological progress, the perfect market environment and policies favoring to the development of emerging industries.

\subsection{Developmental Prospects of Shale Gas in China}

The resources of shale gas in China are mainly distributed in Paleozoic marine shale in the South China, and the reservoir bed are characterized by strong tectonic reworking, complex stress, buried deep and complicated surface conditions [17]. In addition, some continental sedimentary basins, such as Songliao basin, Erdos basin, Turpan Hami basin and Junggar basin, have shale beds with the conditions for the enrichment of shale gas. The most favourable metallogenic zone of shale gas resources is distributed in the Qijiang County, Wansheng County, Nanchuan County, Wulong County, Pengshui County, Youyang County, Xiushan County, Wuxi County and other counties in Chongqing City, therefore, which been identified as the first batch of field exploration target

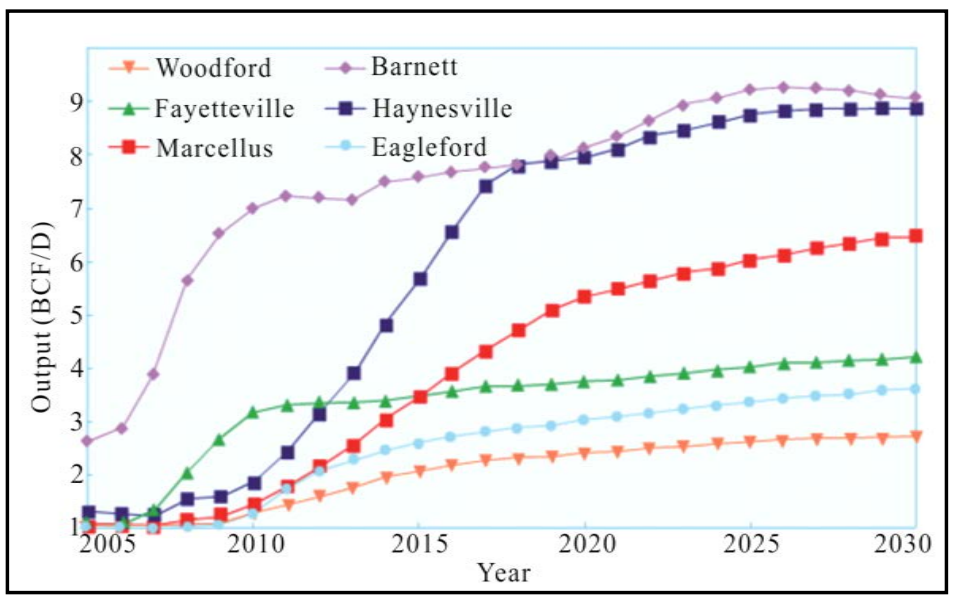

Figure 2. Forecast of the shale gas productions of the USA (after US Energy Information Administration, 2015 [16]). 
area. "Development of gas shale during the Twelfth Five" has been released in March 16, 2012. This plan proposed that the domestic production of shale gas will reach 6.5 billion cubic meters by 2015, and will be expected up to 60 - 100 billion cubic meters. However, the data from the Ministry of land and resources show that the implement extent of the shale gas resources to implement the extent and the reliability of resource data are relatively low, then, the gap between China and the USA is very obvious.

"The challenges of the shale gas market of China in 2015", released by the Zhiyan consultant, show that the shale gas survey in China has been invested more than 7 billion RMB, and more than 80 of construction drillings and more than 20 of the horizontal wells have been finished. 15 million cubic meters of shale gas have been sold in 2012 through the natural gas pipeline network, and the cumulative sales of shale gas are up to 30 million cubic meters. According to the "development plan of shale gas" released by the National Development and Reform Commission, by 2015, the annual output of gas shale in China will up to 6.5 billion cubic meters, and will expected to be 100 billion cubic meters by 2020 . By then, gas shale will account for $10 \%$ of the energy demand in China (Figure 3).

All around the world, mud and shale account for about $60 \%$ of all sedimentary rocks, therefore, shale gas resources have great prospects. The shale gas resources are mainly distributed in North America, Central Asia, China, Latin America, the Middle East, North Africa as well as the former Soviet Union. Among them, the shale gas reserves of China are World first with recoverable reserves of 36 trillion cubic meters. By current consumption levels, these reserves are sufficient to use for more than 300 years.

At present, shale gas potential resources in the USA are 108 trillion cubic meters, among which recoverable resources are 24 trillion cubic meters. The annual number of drilling are more than 100 thousand, and the annual investment are up to one hundred billion US dollars. Moreover, there are thousands of the development companies related to shale gas. On contract, shale gas potential resources in China are 134.4 trillion cubic meters, among which recoverable resources are 25.1 trillion cubic meters. But, the annual number of drilling are less than 50, and the development companies related to shale gas are only five [19]. The above data sources come from the Internet news and papers. Development is ongoing, and data will also be updated, but shale gas development technology is in progress on the whole, and the importance of shale gas is also increasing.

\section{Exploitation Technology of Shale Gas}

During the early stage of the development of the shale gas, the production is mainly from the free shale gas in the cracks of shale and pores of the groundmass. After the extraction of the free natural gas, the pressure of the shale bed decrease gradually, which lead the adsorbed gas in the shale to decompress and became the free gas into the groundmass. Then, these free gas flow into the bottom of the well through the cracks system. This process is the mining of shale gas (Figure 4). However, it should be noted that, although the coexistence of the free and absorbed natural gas, the decompression of the absorbed gas would cause the shale bed to a relative balance during the mining. Therefore, the production of gas shale is characterized by a low output and long cycle [2].

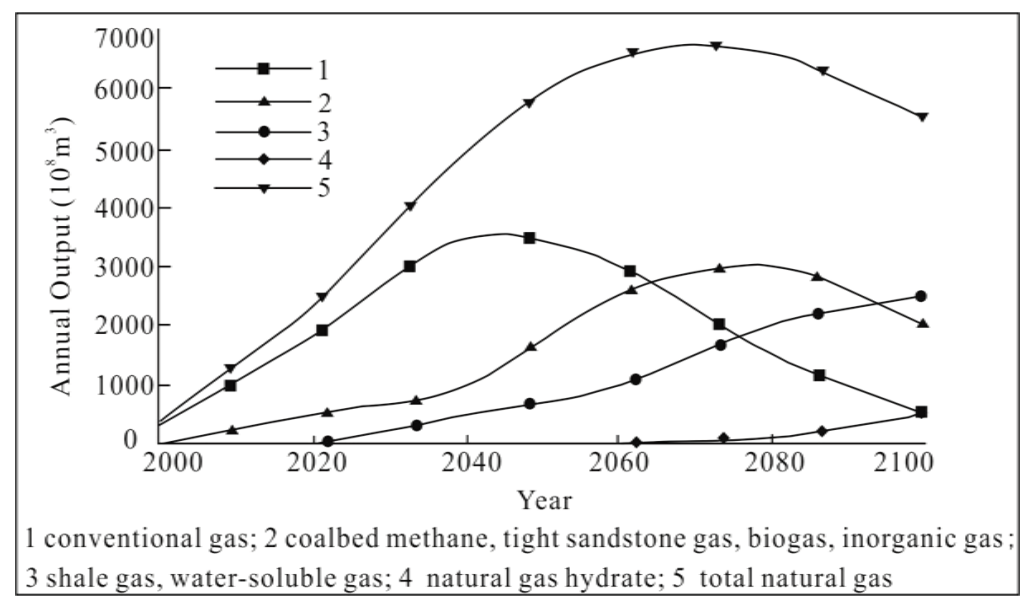

Figure 3. Forecast of the shale gas productions of China (after Fan, 2007 [18]). 


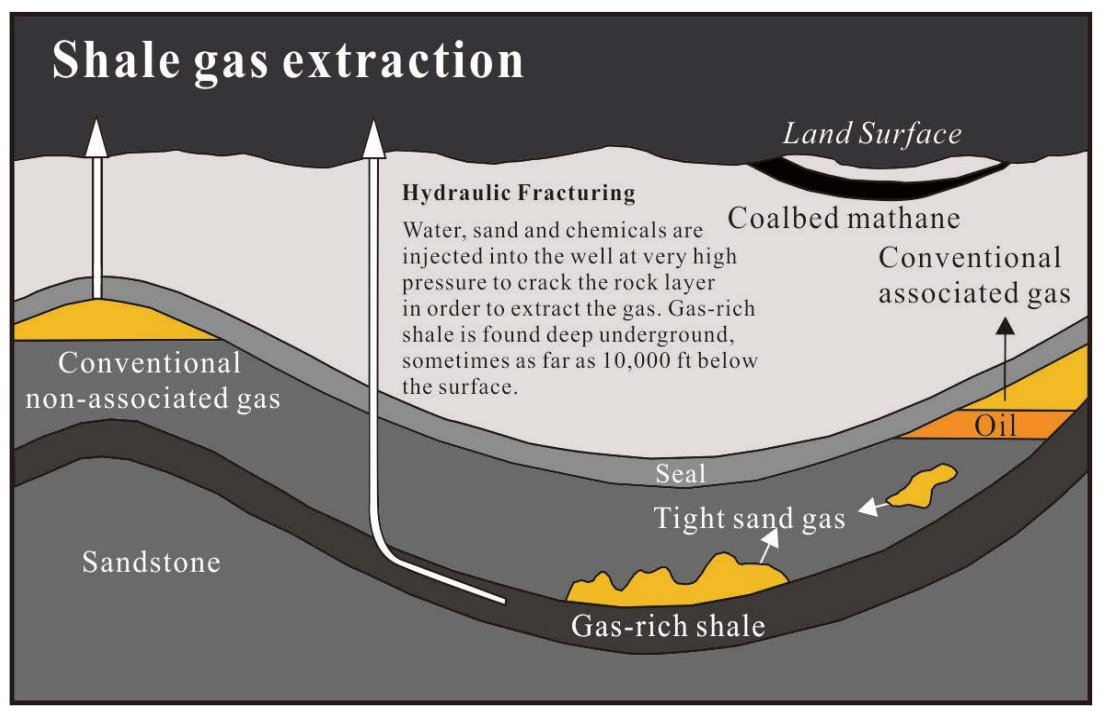

Figure 4. The mining of shale gas (after Reuters, 2013 [20]).

\subsection{Exploitation Technology of Shale Gas in the USA}

The shale gas in the USA is in the developing stage, and has gone through the vertical wells, single-lateral horizontal wells, multi-lateral horizontal wells, cluster wells and PAD horizontal drilling. Horizontal drilling and underbalanced drilling technology accelerate shale gas development process. Foam cementing and casing perforated completion are mainly means of shale gas drilling. In the stimulation aspect, large-scale hydraulic fracturing technology, including water fracturing, vertical well fracturing, horizontal wells sub-fractruing, repeated fracturing and synchronization fracturing, and monitor the fractures from time to time have been used in order to enhance oil recovery [4]. At present, there are some fracturing technologies for the marine reservoirs of shale gas in the USA with well application, which are large slick water fracturing, multistage fracturing and synchronous fracturing and so on. Slickwater and composite fracturing fluid are the main fracturing fluid system [20].

\subsection{Exploitation Technology of Shale Gas in China}

Multiple hydraulic fracturing in horizontal wells technology has been used in the development of shale gas in China. Generally, it is very difficult to quantitatively characterize fracture complexity index for multiple hydraulic fracturing in shale gas horizontal wells, and there is no method available at present on how to optimize fracturing design nowadays. The fracture complexity index characteristic is further analyzed while the distribution density of branch fractures and seepage flow interference overlap area between them along the main hydraulic fracture are taken into consideration [21]. New fracture complexity index is not a range timization and control fracturing treatment parameters, predicting post-fracturing performance and effective period, etc. Based on the systematic works, a new multiple fracturing design method and workflow were established under the condition of horizontal stratification and/or texture fissures. In addition, it is a quantitatively descriptive method of distribution density and length of each natural fractures. This new method was verified in a horizontal shale gas well in Jiaoshiba area and the averaged open-flow capacity rate is $26 \%$ to a great extent.

\section{Study Hotpoint of Shale Gas}

As the rapid development of unconventional natural gas exploration and development, the study of shale fracture is a hot topic. It is ground stress to result in the cracks. When the stress exceeds the strength limit of the rock, the rock will break and form cracks. In high tectonic stress areas, such as the axis of the anticline and syncline as well as the end of declining formation, the stress is large and intensive with concentrated cracks. The stronger rock bed tectonically deformed, the more the cracks develop. In summary, the rock cracks have closely relationship with the geological structure, such as the fold and fault formed in the tectonic movement, the geo- 
metric characteristics, formation and evolution of the regional tectonic, which are also the study Hotpoint of the crack study [22].

According to the different geological origin, the shale fractures can be divided into structural cracks and non structural cracks. The structural cracks can be divided into shear crack, tensile shear fracture, slip crack, structural pressolution crack, vertical load crack and vertical differential load crack. Non structural fractures can be divided into diagenetic shrinkage crack, diagenetic pressolution crack, diagenetic pressolution suture line, superpress crack, thermal shrinkage cracks, corrosion cracks and weathering cracks. The formation mechanism of structural fracture is stated as following: the rock bed deforms, displaces and changes sequence under the horizontal stresses. When the stress exceeds the strength limit of the rock, the rock would breaks down. In addition, there is a crack formed during the rock bed lift and unload, which due to the uplift and erosion, unloading, stress releasing, relaxation of the weak surface of rock. The development of structural fractures is closely related to the structural styles, the structural positions and the mechanical properties of the strata [23].

The forces of mud-shale in the ground can be divided into three types: the overlying rock pressure, the maximum lateral stress and the lateral minimum stress. The overlying rock pressure perpendicular to rock bed is the maximum principal stress, while the lateral minimum stress parallel to rock bed is the minimum principal stress. According to the analysis of rock mechanics, the fractures are generally perpendicular to the minimum principal stress, so the structural fractures in the shale are generally developed in the right angle direction. This is consistent with the results of electrical test. We often see the cracks perpendicular to rock bed in the core, but there are rare cracks parallel to rock bed. Even if there is, these cracks are mostly formed after the decompression, because the cracks parallel to rock bed are easy to close under the pressure of the overlying strata [24]. The shape and orientation of hydraulic fractures are dependent on the relative size of vertical and horizontal principal stresses. Therefore, we must confirm these stresses before the fracturing design (Figure 5).

\section{Problems in the Development of Shale Gas in China}

Shale gas development in the United States also has a lot of problems: there are uncertainty in shale oil and gas resource quantity, risk of ecological environment in the process of shale gas exploitation and controversy of hydraulic fracturing technology. The exploitation of shale gas is later in China than the United States, and because of the lack of experiment, there are more problems in the development of the shale gas besides those problems in the United States [25]. Firstly, the basic theory and experimental research of shale gas are still very weak in China, especially the experiment testing and selection evaluation in the early stage of the development of shale gas (Table 2).

Many studies are limited to the comparison of the geochemical and geological data of the typical shale basin between China and the USA, while the simulated experiments and further studies have not been carried out for the microscopic mechanism of the formation of shale gas as well as the characteristics of the shale rock. At the same time, the Hull anisotropy of shale is much stronger than that of sandstone, therefore, we is still exploring the suitable evaluation method for shale gas resources for China. It is different between China and the USA in

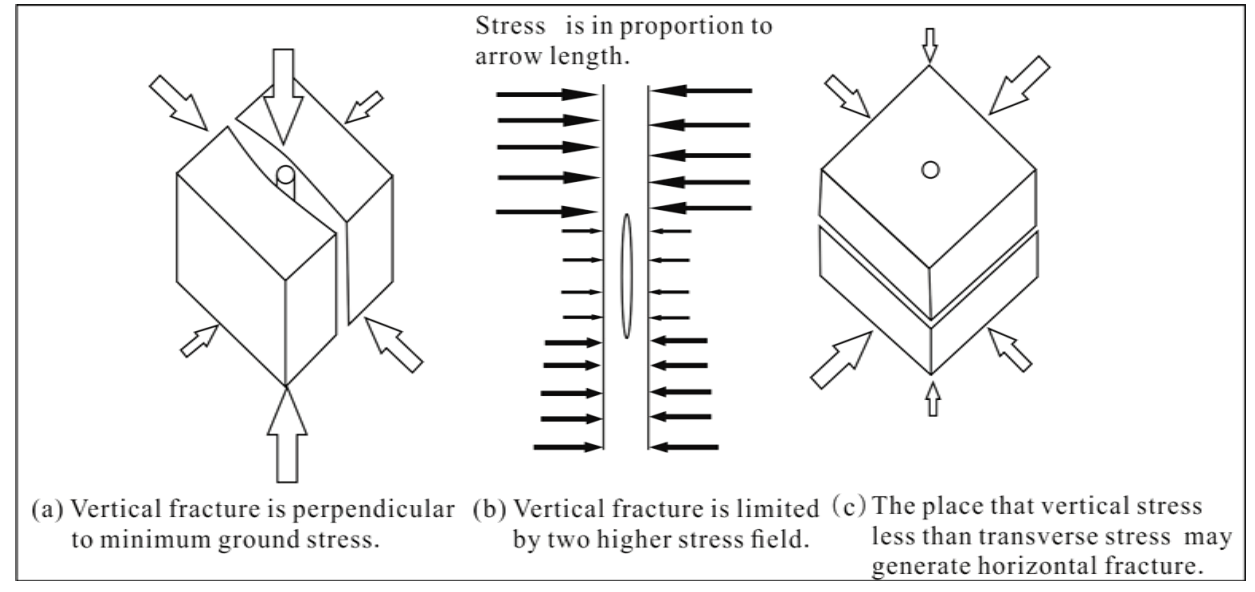

Figure 5. Effect of ground stress field on crack propagation. 


\begin{tabular}{|c|c|c|c|c|c|c|c|c|c|}
\hline Shale & $\begin{array}{l}\text { Age of } \\
\text { Shale }\end{array}$ & Depth/m & $\begin{array}{c}\text { Effective } \\
\text { Thickness/m }\end{array}$ & TOC/\% & Ro/\% & $\begin{array}{c}\text { Quartz } \\
\text { Content/\% }\end{array}$ & $\begin{array}{c}\text { Total } \\
\text { Porosity/\% }\end{array}$ & $\begin{array}{l}\text { Gas Content/ } \\
\left(\mathrm{m}^{3} \cdot \mathrm{t}^{-1}\right)\end{array}$ & $\begin{array}{c}\text { Resource } \\
\text { Abundance/ } \\
\left(10^{8} \mathrm{~m}^{3} \cdot \mathrm{km}^{-2}\right)\end{array}$ \\
\hline Barnett & Miss. & 1981 - 2926 & $30.00-183.00$ & $2.00-7.00$ & $1.10-2.00$ & $35-50$ & $4.00-5.00$ & $8.50-9.91$ & 7.15 \\
\hline Fayetteville & Miss. & 305 - 2287 & $6.10-76.20$ & $2.00-9.80$ & $1.20-4.00$ & & $2.00-8.00$ & $1.70-6.23$ & 6.30 \\
\hline Haynesville & $\mathrm{J}_{3}$ & 3048 - 4155 & 616.00 - 91.44 & $0.50-4.00$ & $2.20-3.20$ & & $8.00-9.00$ & $2.83-9.34$ & 8.71 \\
\hline Woodford & $\mathrm{D}_{3}$ & 1829 - 3353 & 36.58 - 67.10 & $1.00-14.00$ & $1.10-3.00$ & $60-80$ & $3.00-9.00$ & $5.66-8.50$ & 2.29 \\
\hline Antrim & $\mathrm{D}_{3}$ & $183-732$ & $21.00-37.00$ & $1.00-20.00$ & $0.40-0.60$ & $20-41$ & 9.00 & $1.13-2.83$ & 0.69 \\
\hline Lewis & $\mathrm{K}_{2}$ & 914 - 1829 & $61.00-91.00$ & $0.45-2.50$ & $1.60-1.90$ & & $3.00-55.00$ & $0.40-1.30$ & 1.74 \\
\hline Marcellus & $\mathrm{D}_{2}$ & 475 - 2591 & $15.20-304.00$ & $3.00-12.00$ & $1.50-3.00$ & $50-70$ & 10.00 & $1.70-2.83$ & 1.73 \\
\hline Montney & $\mathrm{T}$ & $400-4400$ & 30.00 & $1.20-1.60$ & $1.75-3.75$ & $50-70$ & $5.00-9.50$ & 0.44 & \\
\hline $\begin{array}{l}\text { Qiongzhusi } \\
\text { Formation }\end{array}$ & $-\mathrm{C}_{1} \mathrm{q}$ & $2600-4600$ & $20.00-80.00$ & $2.30-4.20$ & $1.50-5.70$ & $28-56$ & $1.46-2.61$ & $1.17-6.02$ & $0.90-2.30$ \\
\hline $\begin{array}{l}\text { Longmaxi } \\
\text { Formation }\end{array}$ & $\mathrm{S}_{1} \mathrm{l}$ & $1600-4200$ & $20.00-100.00$ & $1.60-3.60$ & $1.88-4.36$ & $24-44$ & $1.00-5.00$ & $1.73-3.28$ & $1.00-2.50$ \\
\hline
\end{tabular}

the geological conditions of formation, exploration degree and exploration procedure of shale gas, then it is unreasonable for China to directly use the mature evaluation and selection methods in the USA. The reliability of resource evaluation method for shale gas depends on the precision of the selection of key parameters. In turn, this precision depends on the input of the exploration as well as scientific and reasonable experimental analysis. The volume method used in the present stage is suitable for the shale gas evaluation with continuous distribution. However, due to the existence of heterogeneity of shale, the effective volume of shale is difficult to be determined [26].

Secondly, the immensely difficult exploitation technical requirements are required for the late stage of shale gas development due to the poor physical property and very low permeability of shale gas. The mining practice in the USA suggested that, breakthrough of some exploitation technologies is significant for the development of the shale gas industry, which include horizontal well drilling, hydraulic multi interval fracturing, refracturing, simultaneous fracturing and comprehensive monitoring of fractures and so on. However, the shale gas buried generally deeper in China, which lead to more difficult to the development of shale gas [2]. Although there are relatively complete infrastructures for the production of natural gas in China, these facilities can't be fully utilized to the development and utilization of shale gas. Furthermore, the distances between shale gas reservoir and conventional oil field, production and consumption and so on also affect the development of shale gas. The infrastructure of natural gas and shale gas is not perfect in China, which cannot fully support the development and utilization of shale gas [15].

At present, the exploration and development of shale gas in China is still in the early stage. In terms of the exploration and development of shale gas, it is unreasonable for China to directly use the foreign experience due to the more complex geological conditions in China than in United States. These are some problems to restrict the development of exploration and development of shale gas in China, such as lack of the key technologies, blank of standards of exploration and development as well as absence of encouraging policies. Then, these fields will be strengthened. In compared, the study of geological theory of shale gas in China is more weakness, and some aspects even seriously hinder the exploration and development of shale gas. The study of geological theory of shale gas plays a key role, and is the fundamental and significant of exploration and development of shale gas. Otherwise, it is impossible to achieve the great progress of the exploration and development of shale gas [26].

\section{Conclusions}

1) The USA led the revolution of shale gas, which brought the quick growing of the output rate and utilization of shale gas in many countries. However, the development of shale gas in China is just started, and is still in the 
exploration and preparation stage of resource assessment and exploration.

2) The development of shale gas shale is system engineering, including many key technologies such as hydraulic fracturing technology, horizontal drilling technology, selection evaluation techniques, experimental analysis technology, micro seismic monitoring technology, logging interpretation technology and three seismic technologies.

3) The exploitation technologies of shale gas have gone through the vertical wells, single-lateral horizontal wells, multi-lateral horizontal wells, cluster wells and PAD horizontal drilling. Horizontal drilling and underbalanced drilling technology accelerate shale gas development process. Foam cementing and casing perforated completion are mainly means of shale gas drilling.

4) Because the tectonic stress is the fundamental cause of the development of the fracture, the study of mud-shale rock fracture is very important. Lithomechanics suggests that the fractures are generally perpendicular to the minimum principal stress, and the structural fractures in the shale are generally developed in the right angle direction with rock bed.

5) The basic theory and experimental research of shale gas in China are still very weak. Therefore, it is unreasonable for China to directly use the foreign experience. It is very important to carrying out the compositive study of geological theory for the development of shale gas.

\section{References}

[1] Curtis, J.B. (2002) Fractured Shale-Gas Systems. AAPG Bulletin, 86, 1921-1938.

[2] Xu, G.S., Xu, Z.X., Duan, L., Yuan, H.F. and Zhang, W. (2011) Status and Development Tendency of Shale Gas Research. Journal of Chengdu University of Technology (Science \& Technology Edition), 38, 603-610. (In Chinese).

[3] Location of World's Shale Gas Distribution (2014) World Resources Institute. http://www.wri.org/water-for-shale

[4] Yang, D.K., Wang, Y., Liu, Q.S., Luo, Y., Wang, Y. and Liu, T. (2012) The Development of Shale Gas Production Technologies in Foreign and Domestic. Petrochemical Industry Application, 31, 1-4. (In Chinese).

[5] Schenk, C.J. and Pollastro, R.M. (2001) Natural Gas Production in the United States. National Assessment of Oil and Gas Series. US Geological Survey Fact Sheet F.S. 113-01.

[6] Mouawad, J. (2009) Estimate Places Natural Gas Reserves 35\% Higher. New York Times.

[7] Li, M., Zhang, X.Z., Li, G.M. and Gong, Y.H. (2014) Shale Gas Technological Development Paths Geared to the Needs of Hunan Province. Coal Geology of China, 26, 70-74. (In Chinese).

[8] Chen, S., Zhu, Y., Qin, Y., Wang, H., Liu, H. and Fang, J. (2014) Reservoir Evaluation of the Lower Silurian Longmaxi Formation Shale Gas in the Southern Sichuan Basin of China. Marine and Petroleum Geology, 57, 619-630. http://dx.doi.org/10.1016/j.marpetgeo.2014.07.008

[9] Hao, F., Zou, H. and Lu, Y. (2013) Mechanisms of Shale Gas Storage: Implications for Shale Gas Exploration in China. AAPG Bulletin, 97, 1325-1346. http://dx.doi.org/10.1306/02141312091

[10] Li, S.Z., Jiang, W.L., Wang, Q. and Liu, L.J. (2013) Research Status and Currently Existent Problems of Shale Gas Geological Survey and Evaluation in China. Geological Bulletin of China, 32, 1440-1446. (In Chinese).

[11] Zou, C. (2013) Chapter 5-Shale Gas. In: Zou, C., Ed., Unconventional Petroleum Geology, Elsevier, Boston, 149-190. http://dx.doi.org/10.1016/B978-0-12-397162-3.00005-0

[12] Zou, C., Dong, D., Wang, S., Li, J., Li, X., Wang, Y., Li, D. and Cheng, K. (2010) Geological Characteristics and Resource Potential of Shale Gas in China. Petroleum Exploration and Development, 37, 641-653. http://dx.doi.org/10.1016/S1876-3804(11)60001-3

[13] Ma, C., Ning, N., Wang, H.Y., Bai, W.H. and Liang, F. (2014) Exploration Prospect of Shale Gas in Niu Titang Formation, Western Hunan-Eastern Guizhou. Special Oil and Gas Reservoirs, 21, 38-41. (In Chinese)

[14] Ma, R.L. (2013) The Geological Characteristics of the Argillutite Formation and Potentiality for the Exploration of the Shale Gas in Central Hunan, Southeastern Hunan and Northeastern Hunan. Chengdu University of Technology, Chengdu. (In Chinese)

[15] Pan, H. and Mao, J. (2014) Study on the Utilization of China’s Shale Gas. Journal of Industrial Technological Economics, 244, 3-12. (In Chinese)

[16] US Energy Information Administration (2015) World Shale Resource Assessments. http://www.eia.gov/analysis/studies/worldshalegas/

[17] Guo, Q., Zhang, J.T., Shen, F., Wu, J.Q., He, D.P. and Ding, H.M. (2014) Fracturing Technology Status of Continental Shale Gas Reservior in Ordos Basin. Journal of Yanan University (Natural Science Edition), 33, 78-81. (In Chinese) 
[18] Fan, B.J. (2007) Resource and Prospect Analysis of Unconventional Gas in China. China University of Petroleum, Beijing.

[19] Ruud, W. (2014) US Shale Gas Production Outlook Based on Well Roll-Out Rate Scenarios. Applied Energy, 124, 283-297. http://dx.doi.org/10.1016/j.apenergy.2014.02.058

[20] Guo, T.L. and Zhang, H.R. (2014) Formation and Enrichment Mode of Jiaoshiba Shale Gas Field, Sichuan Basin. Petroleum Exploration and Development, 41, 28-36. (In Chinese) http://dx.doi.org/10.1016/s1876-3804(14)60003-3

[21] Jiang, T.X., Bian, X.B., Yuan, K. and Zhou, L.B. (2014) A New Method in Staged Fracturing Design Optimization for Shale Gas Horizontal Wells. Petroleum Drilling Techniques, 42, 1-6. (In Chinese)

[22] Cai, Z.X. (2013) Paleo-Structural Stress Field Simulation for Fracture Prediction and Its Application. Science Technology and Engineering, 13, 446-456. (In Chinese)

[23] Zhang, D.X. and Yang, T.Y. (2015) Environmental Impacts of Hydraulic Fracturing in Shale Gas Development in the United States. Petroleum Exploration and Development, 42, 876-883. http://dx.doi.org/10.1016/S1876-3804(15)30085-9

[24] Yuan, Y.S., Sun, D.S., Li, S.J. and Lin, J.H. (2013) Caledonian Erosion Thickness Reconstruction in the Sichuan Basin. Chinese Journal of Geology, 48, 581-591. (In Chinese)

[25] Tian, L., Wang, Z.M., Krupnick, A. and Liu, X.L. (2014) Stimulating Shale Gas Development in China. A Comparison with the US Experience. Energy Policy, 75, 109-116. http://dx.doi.org/10.1016/j.enpol.2014.07.025

[26] Li, Y., Feng, Y., Liu, H., Zhang, L. and Zhao, S. (2013) Geological Characteristics and Resource Potential of Lacustrine Shale Gas in the Sichuan Basin, SW China. Petroleum Exploration and Development, 40, 454-460. http://dx.doi.org/10.1016/S1876-3804(13)60057-9

[27] Zou, C.N., Dong, D.Z., Wang, S.J., Li, J.Z., Li, X.J., Wang, Y.M., Li, D.H. and Cheng, K.M. (2010) Geological Characteristics, Formation Mechanism and Resource Potential of Shale Gas in China. Petroleum Exploration and Development, 37, 641-665. http://dx.doi.org/10.1016/S1876-3804(11)60001-3 